\title{
Environmental Concerns in Cross-National Context: How Do Mass Publics in Central and Eastern Europe Compare with Other Regions of the World?*
}

\author{
SANDRA T. MARQUART-PYATT** \\ Michigan State University, East Lansing
}

\begin{abstract}
Research examining the globalisation of environmental concern shown in public opinion surveys is currently underspecified, as the countries in Central and Eastern Europe are not explicitly showcased in empirical research. To address this gap in the literature, this research examines two measures of environmental concern, awareness of environmental threats and willingness to sacrifice, emphasising former state socialist countries both in comparison with countries around the globe and across countries located within this regional block. Results reveal that Central and Eastern European countries exhibit unique qualities regarding the content of environmental concern, and that, although the determinants of environmental threat awareness differ to some extent within this region, the social bases of willingness to sacrifice are strikingly similar across the six former state socialist countries in this sample. These results extend prior research and offer important directions for future scholarship.
\end{abstract}

Keywords: environmental concern, environmental values, international comparison, post-socialist countries, Central and Eastern Europe

Sociologický časopis/Czech Sociological Review, 2012, Vol. 48, No. 3: 441-466

\section{Introduction}

Explaining concern for the environment with regard to its emergence and salience across nations has been a topic of social science inquiry for decades. With regard to environmental issues and the range of environmental conditions like pollution with which these are often linked, these feature prominently in global initiatives and have grown in international prominence [UNDP 2010; World Bank 2010]. Whereas researchers argue that environmental concerns expressed by citizens worldwide are complex, multifaceted, and varied, Central and Eastern European countries have largely been overlooked in cross-national scholarship. This research seeks to fill this gap in the literature.

* Direct all correspondence to: Sandra T. Marquart-Pyatt, Department of Sociology and Environmental Science and Policy Program, Michigan State University, East Lansing, MI, USA, e-mail: marqua41@msu.edu.

** I thank the special issue editors and anonymous reviewers for comments and critiques.

C Sociologický ústav AV ČR, v.v.i., Praha 2012 
A growing literature seeks to uncover the factors influencing the expression of environmental concerns cross-nationally. Whereas some research suggested that citizens in wealthier or industrialised countries tended to express greater levels of environmental concern based on national material conditions or experiencing a baseline of material security [Inglehart 1995; Kidd and Lee 1997; Diekmann and Franzen 1999; Franzen 2003], another body of scholarship argued instead for the globalisation of environmental concern [Brechin 1999; Dunlap, Gallup and Gallup 1993; Dunlap and Mertig 1995, 1997; Dunlap and York 2008]. Previous research has examined the social bases of environmental concern across countries, including individual characteristics like age, gender, education, income, and knowledge with mixed results. Central and Eastern European countries are not emphasised in prior research, thus making them understudied with regard to how concern for the environment is taking shape within this region and the extent to which similarities are identifiable across countries in this regional block.

This research examines concern for the environment using a cross-national perspective that places Central and Eastern European (CEE) countries squarely in focus. The article begins by reviewing cross-national research on environmental concern, outlining individual-level factors and the importance of regional comparisons. The International Social Survey Programme (ISSP) 2000 Environment dataset, which provides information from over 30000 individuals in 27 countries, is used to examine two measures of environmental concerns uniquely applicable to the former state socialist context: awareness of environmental threats and willingness to sacrifice for the environment. Results reveal that the determinants of environmental threat awareness differ to some extent within this region, and that the determinants of willingness to sacrifice are strikingly similar across the six former state socialist countries in this sample. Results partially confirm expectations from previous research. The findings of this study offer important directions for future scholarship.

\section{Environmental attitudes and concerns in comparative, cross-national perspective}

Environmental concern encompasses a wide range of attitudes, beliefs, behavioural intentions and behaviours. According to Dunlap and Jones [2002: 485], environmental concern can be defined as 'the degree to which people are aware of problems regarding the environment and support efforts to solve them and/or willingness to contribute personally to their solution'. Generally, this research considers a range of environmental concerns like interconnections between the biophysical environment and humanity, attitudes regarding trade-offs between economic growth and environmental protection, willingness to personally contribute to the environment through paying higher prices or taxes or giving time to environmental causes, and personal actions linked with the environment from recycling to engaging in environmental protest. Since the 1990s, researchers have 
explored the globalisation of environmental concern as shown in public opinion data.

Researchers began with the conventional wisdom that environmental concern should be geographically concentrated, present only in wealthy or advanced industrial countries. However, in contrast to geographic concentration among citizens in industrialised nations, research pointed to the wide dispersion of environmental concern globally [Brechin and Kempton 1994, 1997; Dunlap, Gallup and Gallup 1993]. Explanations for the global reach of environmental concern centre on its relation with economic development and the role of context in shaping these views. Simply stated, citizens in some countries express greater levels of environmental concern given a certain baseline level of economic and material security according to national affluence or prosperity [Franzen 2003; Inglehart 1995; Kidd and Lee 1997]. Although citizens' values are proposed to influence environmental concern in advanced industrial contexts like Europe and North America, in contexts like those of industrialising or developing countries the roots of environmental concern were likely harsh, objective environmental conditions like water and air pollution. Inglehart [1995: 61] formulated this 'common sense' approach to explain why support for environmental protection across mass publics around the globe was found, at times, to be greater than the expressed concern of publics in advanced industrial countries, and did so using materialist/postmaterialist values as central aspects for understanding broad-based cultural or value change. The objective problems-subjective values (OPSV) thesis thus advances contextual explanations regarding why environmental concerns exist across the globe rather than being isolated geographically in affluent nations [Inglehart 1995].

This perspective has been critiqued on a number of aspects including its universal applicability and theoretical underpinnings [Brechin 1999; Kidd and Lee 1997]. Dunlap and York [2008] criticise this perspective for its oversimplification and providing an explanation that cannot be empirically evaluated. Recent work examines links between affluence and environmental concern. This research is mixed, showing country differences in attitudes supporting environmental protection as well as the globalisation of environmental concern. To date, empirical examinations of proposed relationships are largely inconclusive [Diekmann and Franzen 1999; Dunlap and York 2008; Franzen 2003; Franzen and Meyer 2010; Gelissen 2007; Givens and Jorgenson 2011; Haller and Hadler 2008].

Throughout this research, scholars emphasise industrialisation, and how the content and expression of environmental concern relates to economic development. In large part, these studies do not consider Central and Eastern European countries as a potentially unique region within which to examine the genesis of environmental concerns or for outlining potentially distinctive attributes of individual countries. Instead, they are generally grouped into categories of either less wealthy or developing countries; thus, they are underspecified and largely under-theorised. Differentiation within industrialised countries has been articulated in a subset of these works, however. For instance, Brechin [1999] suggested countries undergoing political and economic transition may be unique in their 
expression of environmental concerns. Haller and Hadler [2008] found that publics in former communist countries differed with regard to their expressed readiness to make environmental sacrifices or willingness to pay. And, comparing two groups of industrialised countries, Marquart-Pyatt [2008] uncovered broad similarities in the social bases of attitudinal measures of environmental concerns, yet also noted differences for East Germany and Russia, two countries sharing a communist legacy.

Previous scholarship recounts the unique features of post-socialist regimes regarding degraded environmental conditions that resulted from the communist model of industrial development. Many scholars have chronicled deleterious ecological conditions in this region throughout the decades leading up to, including, and following the dismantling of the communist system in 1989 [Baker and Jehlicka 1998; DeBardeleben 1991; Jancar-Webster 1995; Pavlinek and Pickles 2000]. ${ }^{1}$ These works emphasise similar features of environmental degradation across former state socialist countries, yet also stress the possibility of variability across countries within this region. For instance, Pavlinek and Pickles [2000] outline how environmental degradation was integrated in the state socialist model of industrial development and how this translates into a common experience for citizens across contexts. Yet, they also stress the potential for within-region variability or unique attributes of individual countries and regions within countries.

The relation between industrial development processes and the expression of environmental concerns, including its potentially unique attributes in the post-socialist context, is relatively underexplored, however, with one notable exception. DeBardeleben [1997] articulated an expectation of difference between expressions of environmental concern among individuals in former Soviet bloc countries relative to general publics in Western Europe. More specifically, DeBardeleben [1997] argued that views of environmental protection and economic progress are uniquely coupled in this region given the industrial legacy of the communist model of economic development and Soviet ideological legacy. Thus, the expression of environmental concern is not entirely unexpected, but is likely to crystallise around awareness of environmental dangers (e.g. a Chernobyl effect) and is one where notions of economic progress and environmental protection are inextricably linked. Further, with regard to its distribution among the mass public, these environmental concerns should be relatively similar across the social spectrum and effects of socio-demographics, especially material conditions, should be minimal. Results generally confirmed predictions regarding attitudinal differences of individuals when compared across Western capitalist and former communist countries [DeBardeleben 1997].

Given this backdrop, this research adopts a 'regional distinctiveness approach' that advances differences in environmental concerns, specifically with re-

\footnotetext{
${ }^{1}$ A related literature can be identified on the structural and institutional features of countries in CEE regarding income inequality [Bandelj and Mahutga 2010; Mahutga and Bandelj 2008] and carbon emissions [Jorgenson 2011; York 2009].
} 
gard to awareness of environmental threats and willingness to sacrifice, that has particular relevance for post-socialist countries in Central and Eastern Europe. This surpasses limitations of previous cross-national research on environmental concern. That is, whereas some scholarship advances regional or institutional hypotheses tied to economic development, former state socialist countries in Central and Eastern Europe remain underexplored. Research is thus limited in terms of delineating how attitudes and behaviours related to the environment are taking shape in this regional block, including whether existing measures and models accurately convey the breadth and depth of concern for the environment in this region and the countries therein. Research is also underspecified regarding how mass publics in countries in this region compare with other industrialised countries. To address these gaps in the literature, this research examines environmental concern comparatively with emphasis on CEE countries.

According to prior research, there is the possibility of regional differences in both the content of environmental concerns and in the social bases affecting its expression. This research examines how the composition of two different multidimensional measures of environmental concerns, awareness of environmental threats and willingness to sacrifice, varies across a sample of 27 countries. Citizens' expressions of environmental threat awareness likely differ across countries and may not be easily clustered based on division into categories of industrialised/industrialising nations. While previous research like the OPSV thesis would predict that environmental threat awareness is likely higher in developing countries compared with industrial nations, this research offers an important caveat to this expectation-publics in former state socialist countries are also likely to evince greater environmental threat awareness. Regional differences for willingness to sacrifice are also likely to vary; however, the pattern is likely to conform to that anticipated by previous research: greater levels of willingness to sacrifice in advanced industrial countries, and lower levels in developing countries. An expected difference is also likely for former state socialist countries given the rapid social changes transpiring over the decades leading up to 2000, the year of survey data collection.

Following scrutiny of the content or composition of environmental concern comparatively, this study then investigates the determinants or social bases of environmental concern in six former state socialist countries. According to previous research, individual resources and socio-demographics are anticipated to affect environmental concerns, with some differences linked with the measure of environmental concern. That is, education is posited to be positively related with environmental concerns, and age is anticipated to be inversely related to environmental threat awareness and positively related to willingness to sacrifice. In line with prior research, relations between knowledge and environmental threat awareness are anticipated, and environmental beliefs, knowledge and attitudes are hypothesised to positively affect willingness to sacrifice for the environment. 


\section{The social bases of environmental concern}

Environmental concerns may be affected by an individual's surrounding socioeconomic environment, including social characteristics and personal, formative experiences. Research examining the social bases of environmental concern specifies position in the social structure (i.e. education and income), knowledge and socio-demographic variables as key predictors. In this research, education fosters environmental concern through exposure to educational systems instilling norms and values or through psychological effects, either of which can include exposure to environmental awareness [Dietz, Stern and Guagnano 1998; Dunlap, Xiao and McCright 2002; Klineberg, McKeever and Rothenbach 1998]. Expressing environmental concern is also theorised as more likely among those with higher levels of income [Jones and Dunlap 1992; Klineberg, McKeever and Rothenbach 1998]. Greater knowledge is related to higher levels of environmental concern [Blocker and Eckberg 1997]. Socio-demographic factors including age, gender, and place of residence are advanced as influential factors [Dietz, Stern and Guagnano 1998; Dunlap, Xiao and McCright 2002; Jones and Dunlap 1992]. Younger individuals are more likely to express pro-environmental attitudes [Dunlap et al. 2000; Jones and Dunlap 1992; Klineberg, McKeever and Rothenbach 1998], differences between men and women are shown regarding environmental concern [Dietz, Kalof and Stern 2002], and urban residents tend to exhibit higher levels of environmental concern [Jones and Dunlap 1992].

Many of these relationships have also been confirmed cross-nationally. For instance, research supports expectations regarding education and age, where more highly educated and younger respondents demonstrate greater degrees of environmental concern across nations [Gelissen 2007; Haller and Hadler 2008; Kemmelmeier, Krol and Kim 2002; Marquart-Pyatt 2007, 2008; Xiao and Dunlap 2007]. In some nations, compared with males, females have higher concern for the environment [Kemmelmeier, Krol and Kim 2002; Xiao and Dunlap 2007]. And, income and knowledge have been shown to affect environmental concerns cross-nationally [Gelissen 2007; Haller and Hadler 2008; Marquart-Pyatt 2008]. There appears to be an emerging consensus regarding influential factors crossnationally that includes education and income, knowledge, and socio-demographic variables like age, gender, and urban residence.

\section{Data and methods}

The data are from the International Social Survey Programme (ISSP) 2000: Environment [ISSP 2003]. Data from 30139 individuals in 27 countries are used in the analyses: Austria, Britain, Bulgaria, Canada, Chile, the Czech Republic, Denmark, former East Germany, Finland, Ireland, Israel, Japan, Latvia, Mexico, the Netherlands, New Zealand, Northern Ireland, Norway, Philippines, Portugal, Russia, Slovenia, Spain, Sweden, Switzerland, the United States, and former 
West Germany. Six countries are located in Central and Eastern Europe and the former Soviet Union, thirteen are Western European nations, and eight are from other regions of the world including North America, Latin America and Asia. In this section, the measurement of all variables and the methodological approach, structural equation modelling (SEM), are discussed. ${ }^{2}$

The ISSP 2000 Environment survey asks a broad array of questions on environmental attitudes, beliefs, behavioural intentions, and behaviours [ISSP 2003]. To measure environmental concerns, two latent constructs are created based on their broad scope and previous research as well as their unique application in the former state socialist context. Using SEM, specifically confirmatory factor analysis (CFA), both latent variables were created for the pooled sample of countries and for each country individually, with higher values on each set of items indicating a pro-environmental response. SEM is a technique that incorporates measurement error and provides a comprehensive assessment of indicators used in latent variable measures [Marquart-Pyatt 2007, 2008; Xiao and Dunlap 2007]. An SEM approach articulates environmental concerns as multifaceted and complex, which is essential when taking into account mass publics in regions where there are threatening environmental conditions like pollution and conflicting issues regarding trade-offs between economic realities, environmental issues, institutional attributes, and personal beliefs. Results from confirmatory factor analyses demonstrate support for these two latent constructs across all twenty-seven countries pooled and for each of the countries individually. ${ }^{3}$

'Awareness of environmental threats' contains five attitudinal items showing recognition of consequences of human societies' influences on the environment. Questionnaire items gauge respondents' degree of concern with the environmental impacts from numerous activities of modern, industrial societies. Respondents were asked: 'In general, do you think (Air pollution caused by cars; Air pollution caused by industry (scaled); Pollution of country's rivers, lakes, and streams; Pesticides and chemicals used in farming; The rise in the world's temperature caused by the 'greenhouse effect'), is extremely dangerous for the environment, very dangerous, somewhat dangerous, not very dangerous, or not dangerous at all for

\footnotetext{
2 To preserve sample sizes, missing data were accounted for using multiple imputation, specifically the EM algorithm [Allison 2002]. SAS 9.2 was used to complete the structural equation modelling analyses (i.e. confirmatory factor analyses). Analyses were also completed using listwise deletion as a robustness check. Results are similar across alternate specifications. Results using the imputed data are reported here to retain the full samples.

${ }^{3}$ CFAs were completed in a number of stages for each latent variable. Latent constructs were first tested in the pooled sample of 30139 individuals, as described in the text. CFAs were also conducted for each of the 27 countries individually. These results indicate very good to excellent fit for all twenty-seven countries individually for environmental threat awareness and willingness to sacrifice. In addition, multigroup CFAs demonstrate configural and metric invariance of both measures of environmental concerns [Bollen 1989; Cheung and Rensvold 2002]. Theoretically-derived correlated errors are included for each latent measure as appropriate. More information is available upon request.
} 
the environment.' Higher values on this construct indicate pro-environmental response (Cronbach's alpha $=.82$ ). CFA results including component and overall model fit statistics indicate excellent fit of environmental threat awareness. Regarding component fit, standardised factor loadings range from 0.633 to 0.815 and the unstandardised factor loadings from 0.857 to 1.000 (all significant, $p<.001$ ). Overall model fit statistics are excellent-the chi-square value is non-significant, and values for the Incremental Fit Index (IFI) and Adjusted Goodness of Fit Index (AGFI) are both 1.00. Traditionally, values above .95 are recognised to suggest excellent fit [Hu and Bentler 1999]. And, the Root Mean Square Error of Approximation (RMSEA) is .03, with values closer to zero indicative of better fit.

'Willingness to sacrifice' consists of four items communicating a willingness to sacrifice personally in some manner (e.g. time, money) for the environment. The first indicator is, 'How willing would you be to pay much higher prices in order to protect the environment?' The second indicator is, 'How willing would you be to pay much higher taxes in order to protect the environment?' The third indicator is, 'How willing would you be to accept cuts in your standard of living in order to protect the environment?' The fourth statement is, 'I do what is right for the environment whether it costs more money or takes more time'. Items are scaled, so higher scores indicate pro-environmental responses (Cronbach's alpha $=.74)$. CFA results indicate very good fit of willingness to sacrifice. ${ }^{4}$

These measures capture two distinct dimensions of environmental concerns. They are multiple-topic/multiple-expression measures whose components approximate aspects of environmental concern's substantive content in line with previous research [Dunlap and Jones 2002; Xiao and Dunlap 2007]. ${ }^{5}$ Previous research provides a baseline for the two latent constructs in this research [Franzen 2003; Franzen and Meyer 2010; Marquart-Pyatt 2008]. ${ }^{6}$

\section{Independent variables}

Two measures capture position in the social structure. Education is measured with five categories: university education, some college or certificate, completed

\footnotetext{
${ }^{4}$ Regarding component fit for this measure, standardized factor loadings range from 0.319 to 0.821 and unstandardised factor loadings from 0.522 to 1.000 (all significant, $p<.001$ ). Overall model fit statistics are very good-although the chi-square value is significant, the AGFI and IFI are both 1.00, and the RMSEA is .03.

${ }_{5}$ Another approach is rooted in attitude theory, where individual measures can be distinguished based on affective, cognitive, conative, and behavioural components [Dunlap and Jones 2002]. The content of survey items in the ISSP Environment data and the level of generality preclude the use of attitude theory to create distinctions.

6 The latent measure of awareness of environmental threats relies on previous research [Marquart-Pyatt 2008]. Measures used in the latent variable willingness to sacrifice align with previous studies [Franzen 2003; Franzen and Meyer 2010; Haller and Hadler 2008; Marquart-Pyatt 2008].
} 
secondary education, technical or vocational schooling, and primary education. The analyses present results for these as a series of dichotomous variables, with primary education as the reference category. Income is standardised as a $z$-score for comparison across contexts, created individually for each country. The knowledge scale sums responses to five items designed to measure an individual's general level of scientific knowledge. ${ }^{7}$

Age is measured in two ways: in years and as age groups. The age groups relevant to former state socialist countries include: (1) individuals who had at least one year of education during the democratic period (18-29 years of age); (2) individuals who had at least one year of education during the 'thawed' period of Soviet history (30-49); (3) those with no years of education under the thawed or free period (50+ years old)..$^{8}$ In the analyses, these groups are represented as dummy variables, with the youngest age group as the reference category.

Two variables are socio-demographic controls. Respondent's sex is a dummy variable (female $=1$ ). Respondents living in towns with populations over 50000 people are coded as residing in an urban area (urban $=1$ ). A measure of environmental attitudes is also included in the model predicting willingness to sacrifice. Environmental attitudes is a latent construct of six items capturing ideas about the importance of addressing environmental problems and of collective effort for resolving environmental issues and the way in which environmental issues intersect with economic issues, science, and societal progress. CFA results indicate very good fit of this measure across the countries individually (available upon request).

\section{Results}

Table 1 provides descriptive information across the 27 countries in the sample for the nine individual questionnaire items included in the two dimensions of environmental concern. Considerable variation is shown across countries in the individual measures. The values in bold indicate the high and low percentages for each measure. Citizens around the globe show an awareness of environmental threats from the activities of modern, industrial societies according to the first five columns. Percentages are shown for responses to referenced items as being extremely and very dangerous for the environment. This recognition includes

\footnotetext{
${ }^{7}$ Items in the knowledge scale are: 'All man-made chemicals can cause cancer if you eat enough of them'; 'If someone is exposed to any amount of radioactivity, they are certain to die as a result'; 'The greenhouse effect is caused by a hole in the atmosphere.'; 'Antibiotics can kill bacteria but not viruses.'; and 'Every time we use coal or oil or gas, we contribute to the greenhouse effect' [Hayes 2001].

8 This is a conservative coding strategy as it delineates individuals based on receipt of even a single year of education in democratic or thawed time periods. Results are similar across alternative codings like spending 'formative years' under a particular regime and ten-year age cohorts.
} 


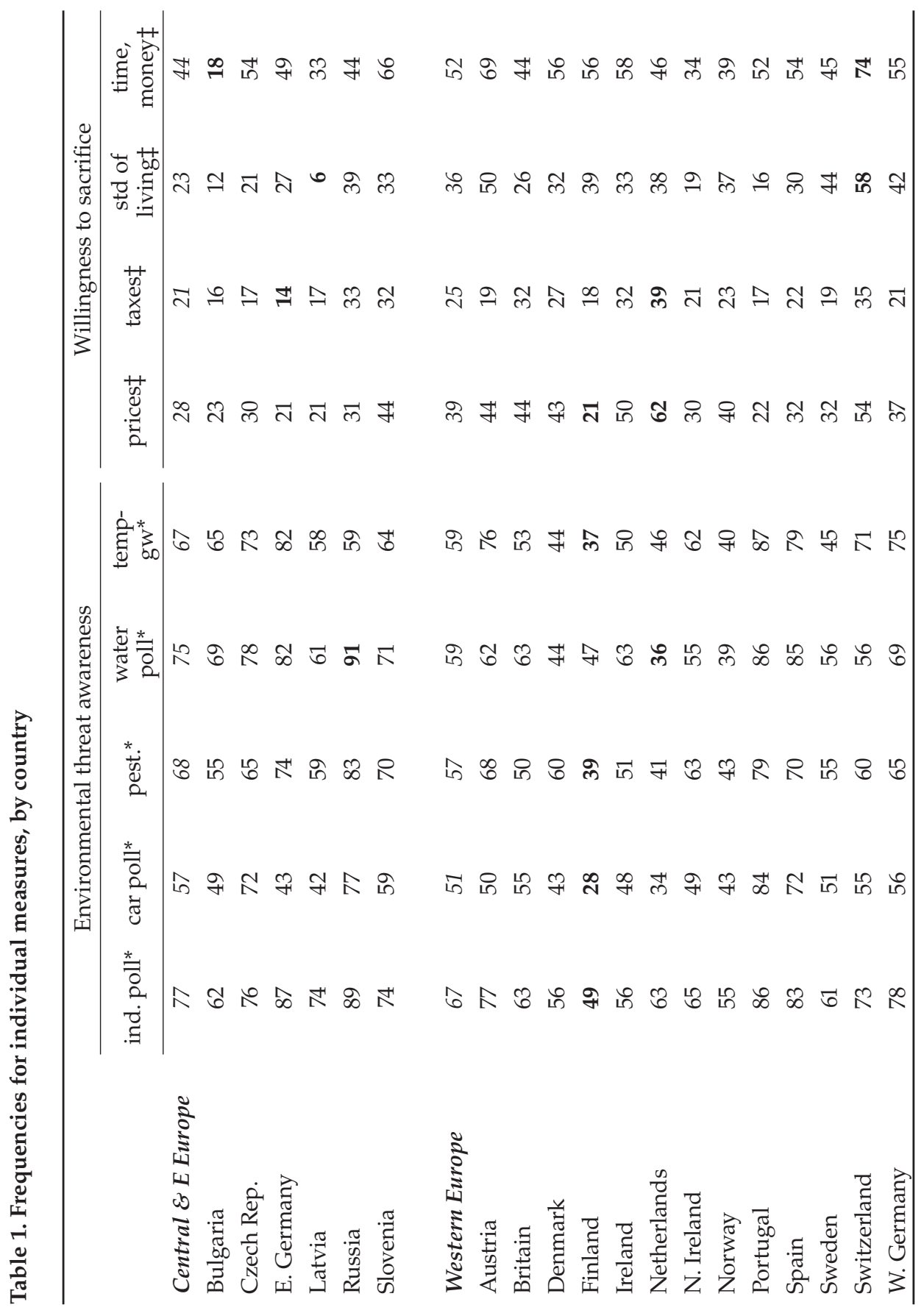




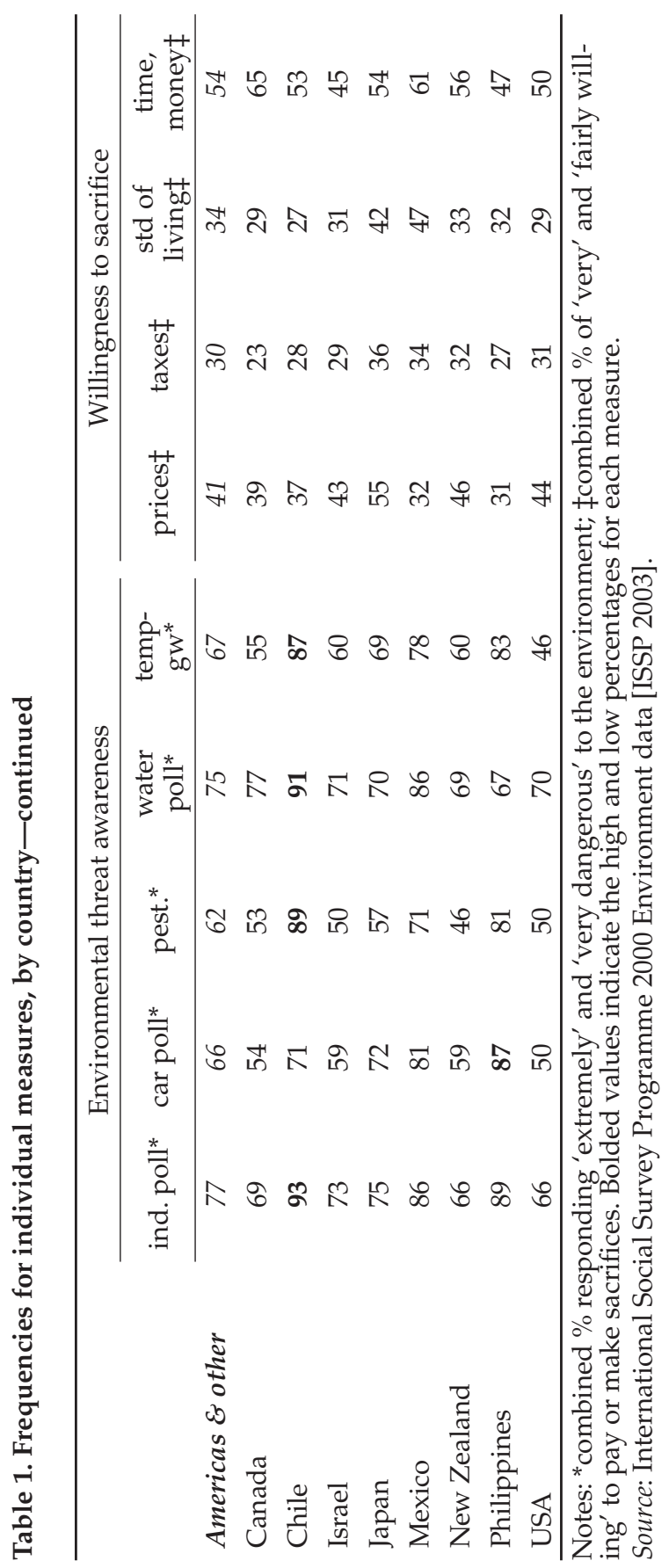


potential harms associated with air pollution from industries, car and water pollution, agricultural pollution, and global warming's effects. In 18 countries, twothirds of the population responded that industrial air pollution was dangerous, with the highest percentage in Chile. For air pollution caused by cars, majorities in most countries responded these are dangerous to the environment, comprising $50 \%$ or more of survey respondents in all but nine countries. For pesticides and chemicals used in farming, majorities of respondents in all but four countries responded they were dangerous, ranging from $89 \%$ in Chile to $39 \%$ in Finland. Similar responses are shown for pollution of rivers, lakes, and streams-majorities responding these are dangerous, except in four countries. Overall, values range from $36 \%$ in the Netherlands to $91 \%$ in Russia and Chile. With regard to global warming, a plurality of survey respondents affirms that rising temperatures are dangerous to the environment, comprising majorities in all but six countries.

When examined as individual countries, there is considerable variation, and former state socialist countries do not appear to be exceptional in their awareness of environmental threats from various pollution sources. However, the basic pattern by region, shown in italics in Table 1, is striking: respondents in $\mathrm{CEE}$ as a group display greater concern about all five measures of environmental threats than respondents in Western Europe. For instance, concern for threats from industrial and water pollution are $77 \%$ and $75 \%$ in CEE and $67 \%$ and $59 \%$ for Western Europe, respectively. These data support the regional distinctiveness approach and provide some support for the OPSV framework, as concerns in CEE countries may be higher given their experience with abject environmental conditions that might heighten such awareness. The communist model of industrial development's emphasis on heavy industry produced severe regional environmental degradation, and citizens in these countries were often exposed to polluted environmental conditions as a result. Although the data are from 2000 and some changes in pollutants were evident during the first decade of the postsocialist transition, heightened levels of concern remain anticipated given the industrial legacy of the former communist system [DeBardeleben 1997; JancarWebster 1995; Pavlinek and Pickles 2000].

The final four columns of Table 1 include percentages for questionnaire items that illustrate a willingness to sacrifice personally for the environment. Percentages are shown for those replying that they are very and/or fairly willing to sacrifice for the environment. Regarding expressed willingness to pay higher prices, majorities were supportive of this in only three countries and pluralities were in twelve countries. Regarding paying higher taxes, in no country in the sample did a majority indicate willingness to do this; pluralities are shown in five countries. Indeed, some of the lowest values are in Bulgaria, the Czech Republic, former East Germany, and Latvia. Similarly, percentages of respondents expressing willingness to accept cuts in their standard of living to protect the environment tend to be lower in former state socialist countries. Pluralities show support for this sentiment in twelve countries, with a majority of Swiss expressing such 
Table 2. Latent variable means and correlations for 'environmental threat awareness' and 'willingness to sacrifice', by country

\begin{tabular}{|c|c|c|c|c|c|c|c|}
\hline & \multicolumn{2}{|c|}{$\begin{array}{c}\text { Envtal threat } \\
\text { awareness }\end{array}$} & \multicolumn{3}{|c|}{ Willingness to sacrifice } & \multicolumn{2}{|c|}{$\begin{array}{l}\text { Correlation b/w } \\
\text { latent constructs }\end{array}$} \\
\hline & Mean & $\begin{array}{l}\text { Std } \\
\text { Dev }\end{array}$ & & Mean & $\begin{array}{l}\text { Std } \\
\text { Dev }\end{array}$ & & \\
\hline Russia & 3.86 & 0.53 & Switzerland & 2.88 & 0.83 & Finland & .43 \\
\hline Portugal & 3.65 & 0.52 & N. Zealand & 2.75 & 1.04 & N. Ireland & .32 \\
\hline N. Zealand & 3.55 & 0.67 & Chile & 2.62 & 1.06 & Denmark & .30 \\
\hline Bulgaria & 3.54 & 0.68 & Denmark & 2.56 & 0.77 & United States & .30 \\
\hline Spain & 3.36 & 0.50 & Finland & 2.54 & 0.87 & Netherlands & .29 \\
\hline Chile & 3.36 & 0.41 & Norway & 2.52 & 0.76 & Norway & .23 \\
\hline United States & 3.30 & 0.63 & Britain & 2.52 & 0.71 & Switzerland & .22 \\
\hline Canada & 3.28 & 0.60 & Japan & 2.51 & 0.59 & Sweden & .21 \\
\hline Philippines & 3.27 & 0.47 & Sweden & 2.50 & 0.57 & N. Zealand & .21 \\
\hline Britain & 3.26 & 0.64 & Israel & 2.50 & 0.66 & Bulgaria & .20 \\
\hline Japan & 3.26 & 0.53 & Slovenia & 2.45 & 0.58 & Slovenia & .20 \\
\hline Switzerland & 3.13 & 0.52 & W. Germany & 2.44 & 0.61 & Ireland & .20 \\
\hline E. Germany & 3.10 & 0.42 & United States & 2.43 & 0.81 & Britain & .19 \\
\hline W. Germany & 3.07 & 0.48 & Latvia & 2.39 & 0.98 & W. Germany & .19 \\
\hline Latvia & 3.05 & 0.52 & Spain & 2.38 & 0.77 & Canada & .19 \\
\hline Mexico & 3.05 & 0.45 & Ireland & 2.35 & 0.81 & Japan & .18 \\
\hline N. Ireland & 3.04 & 0.61 & Russia & 2.34 & 0.86 & Israel & .15 \\
\hline Slovenia & 3.02 & 0.51 & N. Ireland & 2.33 & 0.99 & Czech Rep. & .13 \\
\hline Denmark & 2.98 & 0.62 & Austria & 2.29 & 0.49 & Austria & .13 \\
\hline Ireland & 2.96 & 0.55 & Portugal & 2.26 & 0.98 & Portugal & .12 \\
\hline Sweden & 2.95 & 0.54 & Bulgaria & 2.24 & 0.95 & Spain & .12 \\
\hline Israel & 2.92 & 0.52 & E. Germany & 2.23 & 0.70 & Russia & .11 \\
\hline Czech Rep. & 2.89 & 0.45 & Mexico & 2.15 & 0.77 & Latvia & .03 \\
\hline Finland & 2.76 & 0.77 & Czech Rep. & 2.14 & 0.84 & E. Germany & .02 \\
\hline Netherlands & 2.69 & 0.45 & Canada & 2.14 & 0.56 & Mexico & .01 \\
\hline Austria & 2.68 & 0.46 & Philippines & 2.14 & 0.65 & Chile & .00 \\
\hline Norway & 2.56 & 0.52 & Netherlands & 2.00 & 0.49 & Philippines & .00 \\
\hline Grand mean & 3.14 & & Grand mean & 2.39 & & & \\
\hline
\end{tabular}

Note: Bolded values indicate former state-socialist countries.

Source: Author's calculations from ISSP 2000 Environment data [ISSP 2003]. 
a willingness to sacrifice. Majorities of respondents in sixteen countries and pluralities in ten countries indicate that they make personal sacrifices of time and money for the environment, with an overall range from $18 \%$ in Bulgaria to $74 \%$ in Switzerland. For these items overall, an expressed willingness to sacrifice is not readily embraced by populations around the globe.

As individual countries, there is variation, and former state socialist countries differ somewhat but do not appear to be exceptional in their reported lower willingness to sacrifice for the environment. Respondents from CEE countries do display lower willingness to sacrifice across all questions compared with Western Europe, however. As before, a basic pattern can be identified. For instance, there is less expressed willingness to pay higher prices and accept cuts in standard of living: $28 \%$ and $23 \%$ in CEE and $39 \%$ and $36 \%$ for Western Europe, respectively. This is also not entirely unexpected, however, given what the economic transitions have meant for individual material conditions like income declines, increasing income inequality, and rising unemployment and underemployment [Bandelj and Mahutga 2010; Heyns 2005; Milanovic 1996]. These results partially support the regional distinctiveness approach.

Table 2 contains descriptive information for environmental threat awareness and willingness to sacrifice across the countries in the sample. There are some differences in the ranking of individual countries across the two measures, which range from 0.80 to 4.96 and 0.53 to 5.52 units, respectively, across the countries in the sample. ${ }^{9}$ Using the grand mean value for comparison, only about half of the countries rank consistently, with five countries having above average values for both measures (Britain, Chile, Japan, New Zealand and the US), and eight with values below (Austria, the Czech Republic, East Germany, Ireland, Latvia, Mexico, the Netherlands and Northern Ireland). For awareness of environmental threats, two of the top five countries are former state socialist countries (Russia and Bulgaria), whereas the five lowest ranking countries include only one, the Czech Republic. For willingness to sacrifice, four of the five countries with the highest values are advanced industrial countries. Slovenia is the only former state socialist nation with a value above the grand mean. A brief perusal of country rankings suggests some variability across these measures of environmental concern and provides an initial challenge to anticipated patterns in that countries do not uniformly cluster based on regional or other categorisations linked with industrialisation. They do point to some uniqueness of CEE countries for the measure of willingness to sacrifice, however, as anticipated from prior studies. The final column in the table provides information about relations between these two constructs for each of the 27 countries in the sample. Results reveal these measures to be empirically distinct. Generally, awareness of environmental threats and willingness to sacrifice are positively correlated, with Pearson's correlation coefficients around .20 between the two measures, as shown in the third column of Table 2, ranging from zero (in Chile and Philippines) to .43 (in Finland).

${ }_{9}$ More detailed information for each country is available upon request. 
The next step in the analysis is to model both measures of environmental concern, environmental threat awareness and willingness to sacrifice for the environment, at the individual level to evaluate theoretical expectations. This allows the evaluation of the models across the sample of former state socialist countries as a regional block (i.e. pooled) as well as across each of the six countries separately. Table 3 presents results assessing the first dependent variable, awareness of environmental threats. The first column of Table 3 shows results for the pooled model including country dummy variables (not shown). ${ }^{10}$ An adjusted $R^{2}$ value of .15 and overall model fit statistics from SEM support the model. In sum, of the eleven possible paths affecting awareness of environmental threats, six have significant effects; most are in the expected direction. Although only two are significant, there are positive effects across all education categories on awareness, while income has a negative effect. Knowledge negatively affects awareness of environmental threats. Females, compared with males, and urban residents are more aware of environmental threats. Age did not have a linear effect, but the coefficient was negative for the oldest age group who had received the largest amount of education under the communist system compared with the youngest group who had received the smallest amount. Since coefficients are averaged across countries, however, results from the pooled model cannot tell us how the model performs in each cultural context. Therefore, the model is examined separately for each of the six former state socialist countries.

Table 3 also shows results for each country individually. Overall, results support the model seeking to identify the social bases of environmental threat awareness across six nations. Adjusted $R^{2}$ values, although relatively small, and overall model fit statistics from SEM support the model. For instance, adjusted $R^{2}$ values are between .03 (in East Germany) and .05 (in Latvia), and IFI, CFI, and RMSEA values also generally demonstrate acceptable model fit for these countries [Hu and Bentler 1999]. Comparing across the results for individual countries reveals that no single measure of socio-demographics or individual resources uniformly affects awareness of environmental threats. However, differences across educational categories are notable in the anticipated positive relation, and are shown for those with secondary education compared with primary in four of the six countries, and for those with university education compared with primary education in two (in Bulgaria and Slovenia). Income and knowledge each have significant negative effects in two countries. Although counter to previous research, the knowledge-threat awareness inverse relation appears plausiblethose with greater knowledge have lower environmental threat awareness. Urban residence and being female also have positive effects on awareness of environmental threats for three countries.

\footnotetext{
${ }_{10}$ Russia is the reference category. Pooling observations and including country dummy variables to account for heterogeneity is empirically appropriate as it accounts for clustering but does not attempt to explain it [Marquart-Pyatt 2008; Steenbergen and Jones 2002].
} 


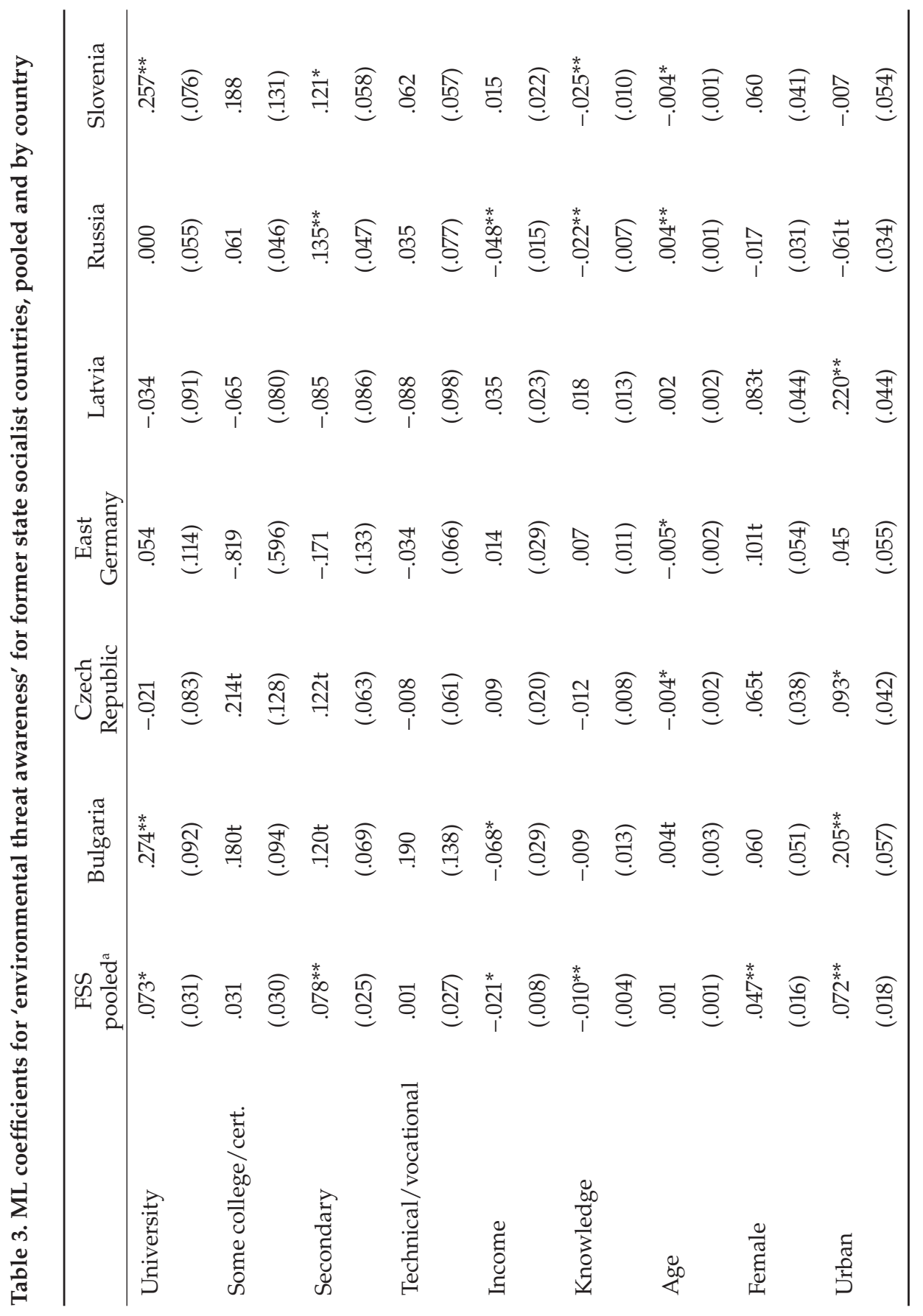




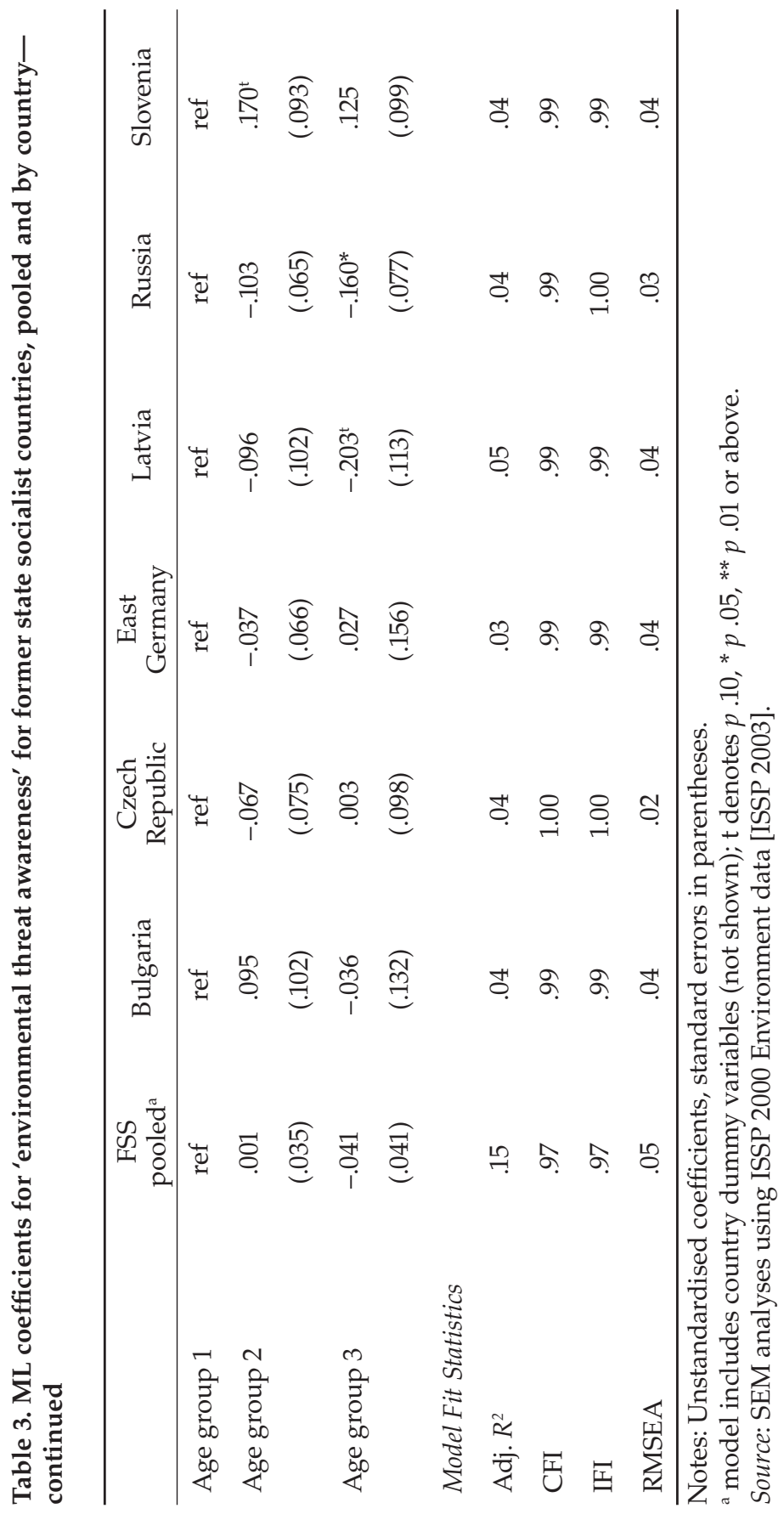




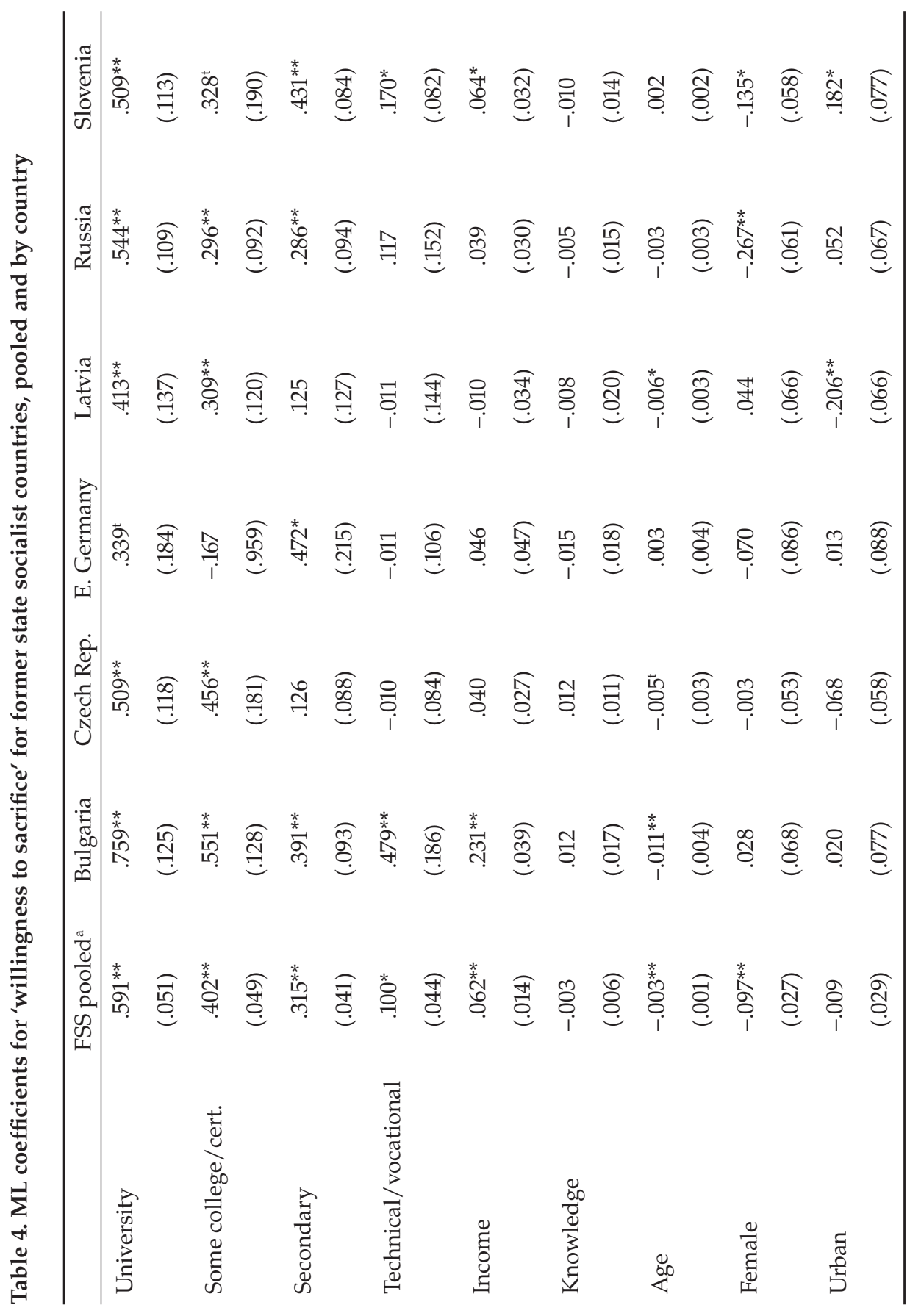




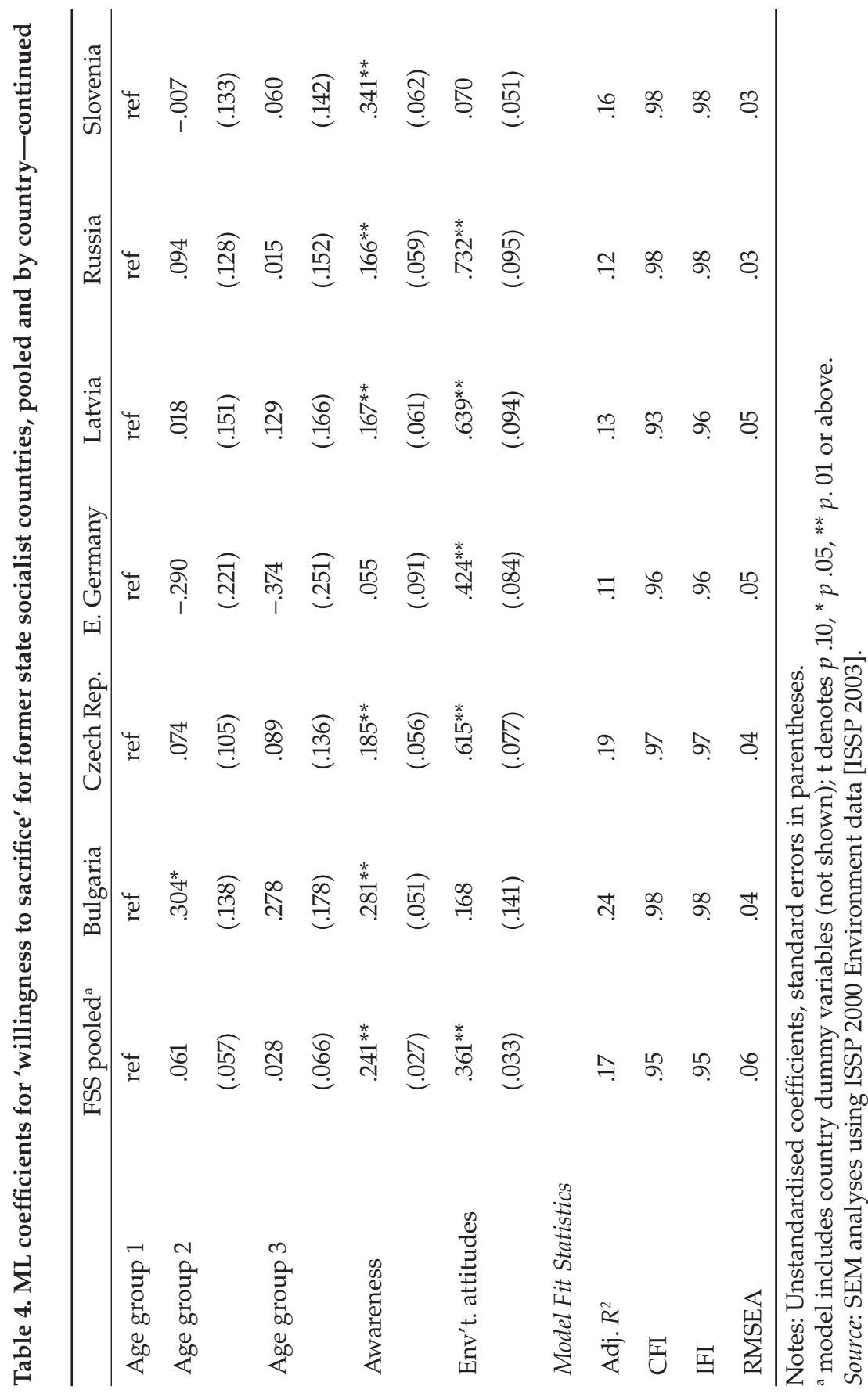


Results for age also point to some interesting differences: its effects are shown in the Czech Republic, East Germany, Russia, and Slovenia for its linear effect, for the oldest age group compared with the youngest in Russia and Latvia, and in Slovenia between the youngest and middle age groups. These linear relations also point to some interesting differences: effects of age are negative in the Czech Republic, East Germany and Slovenia, and positive in Russia. Although results are broadly similar to previous research for education and age [Franzen and Meyer 2010; Marquart-Pyatt 2007, 2008; Xiao and Dunlap 2007], results reveal that the determinants of environmental threat awareness differ to some extent across the six former state socialist countries in this sample.

Table 4 presents results for willingness to sacrifice. The first column shows results for the pooled model including country dummy variables. An adjusted $R^{2}$ value of .17 and overall model fit statistics from SEM support the model. Briefly, nine of the thirteen possible paths affecting willingness to sacrifice have significant effects, and most of these are in the expected direction. All four educational categories have higher expressed willingness to sacrifice, compared with those with a primary education. Income positively affects willingness to sacrifice, and females, compared with males, have lower expressed willingness to sacrifice for the environment. Environmental threat awareness and pro-environmental attitudes positively affect willingness to sacrifice across former state socialist countries. No significant differences are shown between the age groups. As before, given averaged coefficients across countries in the pooled results, the model is examined separately for each country.

Results in Table 4 are also provided for each country individually. Overall, results support the model seeking to identify the social bases of willingness to sacrifice across six nations. Adjusted $R^{2}$ values and overall model fit statistics support the model. For instance, adjusted $R^{2}$ values are between .11 (in East Germany) and .24 (in Bulgaria). IFI, CFI, and RMSEA values also generally demonstrate very good model fit for these countries [Hu and Bentler 1999]. Comparing across results reveals that education has a prominent role, in general terms positively affecting expressed willingness to sacrifice in all six countries. Similarly, awareness of environmental threats and pro-environmental attitudes positively affect willingness to sacrifice in five and four of the six countries, respectively. More limited effects are shown for income, age, being male, and urban residence in two countries each.

Results for age also point to some interesting differences: its effects are negative in Bulgaria and Latvia when measured in years, and only one age group difference was notable between the youngest and middle age group in Bulgaria. The sign of the age effect differs from previous research, and may be attributable to the dynamics of social change in these countries. Net of other effects, a unit increase of environmental threat awareness influences latent levels of willingness to sacrifice by between .166 units in Russia and .341 units in Slovenia across countries, with an average return of .241 units for each latent unit increase. Controlling 
for other variables in the model, a unit increase in latent environmental attitudes has an average return of 371 latent units for each latent unit increase in willingness to sacrifice, with effects ranging from .070 units in Slovenia to .732 units in Russia across countries in the sample. Results thus reveal that the determinants of willingness to sacrifice are similar across the six former state socialist countries in this sample. Results are similar to previous research for education and environmental beliefs and attitudes [Franzen and Meyer 2010; Marquart-Pyatt 2007, 2008; Xiao and Dunlap 2007].

To summarise, two general conclusions may be drawn from the results. First, there are important similarities for CEE countries with regard to the content of environmental threat awareness and willingness to sacrifice expressed by mass publics when compared with other regions. Although there are regional differences in expressed environmental concerns that appear to be related to industrial development, at the same time there is also some variability within regions. Second, results reveal that the social bases of environmental threat awareness differ to some extent, while the determinants of willingness to sacrifice are similar across the six former state socialist countries in this sample. Education is revealed as a key factor in the expression of both measures of environmental concern. However, results also uncover within-region differences in mechanisms affecting public opinion on environmental concerns related to age and urban residence that offer an important caveat to expectations from prior research.

\section{Discussion and conclusion}

This study extended previous cross-national research on environmental concern by emphasising Central and Eastern European countries in comparison with other countries around the globe, and in examining the social bases of two attitudinal measures of environmental concern for this group of six former state socialist countries. Given previous research and the potentially unique constellation of environmental values, beliefs, and attitudes of citizens in this region in the wake of rapid social changes following the dismantling of the communist system, this research investigated two measures of environmental concern, awareness of environmental threats and willingness to sacrifice. Results examining latent measures revealed that former state socialist countries are to some degree exceptional in how awareness of environmental threats and expressed willingness to sacrifice for the environment are coupled. That is, publics in CEE as a group simultaneously display heightened concern about environmental threats and lower willingness to sacrifice personally for the environment. Results indicate that the determinants of environmental concern differ to some degree across these measures. Although education is revealed to be a key factor for both, as anticipated from prior research [Marquart-Pyatt 2007, 2008; Xiao and Dunlap 2007], results uncover within-region differences for socio-demographics like age and urban residence that offer an important caveat to expectations from prior research. The 
results raise important questions for future empirical research. The importance of regional hypotheses and of theorising differences on the basis of countries' institutional characteristics requires further articulation and scrutiny.

This research reveals the uniqueness of former state socialist countries to be twofold: in one sense regarding the composition of environmental concerns and in the second regarding the assumption of similar influential factors on its expression. First, it is vital to measure environmental concern as a latent construct to accurately portray its multifaceted, multi-dimensional features. Differences in country rankings and resulting challenges in identifying patterns across these dimensions of environmental concerns suggest caution for future crossnational, comparative research and emphasise the importance of measurement for future scholarship. Even between latent constructs of environmental concern, however, there is variability - awareness of environmental threats differs from an expressed willingness to sacrifice for the environment. The question of whether this uniqueness extends to other dimensions of environmental concern including to attitudinal measures recognising trade-offs between economic progress and environmental protection or to environmental actions like recycling or signing petitions remains to be addressed.

Second, a further examination of the performance of the model predicting environmental concerns within regions is also required. As an example, although the communist model of industrial development led to severe regional degradation in urban centres [Pickles and Pavlinek 2000], results of this study revealed mixed effects for urban residence on environmental threat awareness-significant in four countries (Bulgaria, the Czech Republic, Latvia, and Russia) and having the largest effect in only one (Latvia). Further, results for age and environmental threat awareness reveal they are not uniform, as anticipated negative relations are shown for the Czech Republic, East Germany and Slovenia, but a positive effect is shown for Russia. Few differences across age groups are found either-the oldest age groups are less aware of environmental threats only in Russia and Latvia, and the middle age group in Slovenia is more aware, pointing to more nuanced examinations of ideological legacy arguments. Results for the second measure, however, point to a more general pattern, where an inverse relation between age and willingness to sacrifice is revealed only in half of the countries, and age group differences are the exception.

Might differing effects for age across CEE countries be explained by age group differences in experiencing particular environmental conditions? Perhaps some age groups may have been recalling past events or situations where either information about environmental pollutants may have not been accessible, environmental conditions were markedly worse, or based on exposure to ideological legacies. Pollution has left an indelible imprint on many urban areas in the former state socialist region, and the same applies to water pollution from agriculture and farming in some areas as well [Pavlinek and Pickles 2000], yet these factors appear to be less salient than, for instance, educational effects on environmental concerns. These issues raise important questions for future empirical research seeking to ex- 
amine how environmental concerns are linked with other dynamic social, political, and economic processes. Combined, these results present an interesting puzzle for future scholarship-to what extent should researchers balance competing expectations about deriving general patterns with identifying exceptional cases? Future research is challenged to strike a balance between articulating common processes in the broadest possible global sense while also being cognizant of within-region variation. That is, it is important to take into account path-dependence arguments in identifying patterns across countries within regions comprising meaningful groups that can be further explored in subsequent studies.

Continued investigation of conceptual models seeking to explain the emergence of environmental concern in challenging contexts like material uncertainty remains important for future research. Regarding expressed willingness to sacrifice, for instance, the questions used in the ISSP dataset highlight just how difficult the realisation of some forms of environmental concern may be, as many CEE citizens experienced material decline in the years leading up to the year of survey data collection and lower levels of some of these measures are not entirely unexpected. Indeed, testing contextual arguments that build socialisation and educational arguments related to the emergence and salience of environmental policy support and environmental actions like energy conservation would contribute to this emerging area of scholarship. Moreover, examining within-regional variation over time in predictors shown to be influential in this study will continue to build cross-national, comparative work on concern for the environment. Central and Eastern European countries have unique attributes relative to other industrialised countries related to the state socialist past and the communist model of industrial development, yet within this regional block there are differences in the determinants of environmental concern. Apart from the role of education, there are some notable differences across countries in this region regarding factors affecting environmental threat awareness compared with factors affecting willingness to sacrifice. Future scholarship specifying contextual factors like environmental conditions and economic and political institutions that seek to explore possible dimensions of difference across regions would be a fruitful extension of this work.

Building models to investigate contextual arguments are vital for moving the literature forward. Articulating hypotheses that advance individual-level and institutional-level attributes pertaining to the sources and consequences of environmental concern are important extensions of this research. Gathering longitudinal data is also essential for such nuanced explorations to uncover the extent to which the composition and expression of environmental concerns are systemic, link with individual value change, or are taking shape dynamically. It is imperative for future research to expand data-gathering initiatives to include a larger number of countries to extend this research's findings that concern for the environment is far-reaching, varied, and has somewhat unique regional articulations. Further expansion across time and space and towards including additional attitudinal and behavioural measures of environmental concern are vital extensions of this scholarship. 
SANDRA MARQUART-PyATt is an assistant professor in Sociology and the Environmental Science and Policy Program at Michigan State University in East Lansing, MI, USA. Her research expertise is in comparative social change, environmental sociology, political sociology, and quantitative methods. Her current work focuses on identifying cross-national patterns on environmental attitudes, beliefs, behavioural intentions, and behaviours including climate change, environmental concern and sustainability.

\section{References}

Allison, Paul. 2002. Missing Data. Thousand Oaks, CA: Sage Publications.

Baker, Susan and Petr Jehlicka. 1998. Dilemmas of Transition: The Environment, Democracy and Economic Reform in East Central Europe. Portland, OR: Frank Cass Publishers.

Bandelj, Nina and Matthew Mahutga. 2010. 'How Socio-economic Change Shapes Income Inequality in Post-socialist Europe.' Social Forces 88 (5): 2133-2162.

Blocker, T. Jean and Douglas L. Eckberg. 1997. 'Gender and Environmentalism: Results from the 1993 General Social Survey.' Social Science Quarterly 78: 841-858.

Bollen, Kenneth. 1989. Structural Equations with Latent Variables. New York: Wiley.

Brechin, Steven. 1999. 'Objective Problems, Subjective Values, and Global Environmentalism: Evaluating the Postmaterialist Argument and Challenging a New Explanation.' Social Science Quarterly 84 (4): 793-809.

Brechin, Steven and Willet Kempton. 1994. 'Global Environmentalism: A Challenge to the Postmaterialism Thesis?' Social Science Quarterly 75: 245-269.

Brechin, Steven and Willet Kempton. 1997. 'Beyond Postmaterialist Values: National versus Individual Explanations of Global Environmentalism.' Social Science Quarterly 78: 16-20.

Cheung, Gordon and Roger Rensvold. 2002. 'Evaluating Goodness-of-Fit Indexes for Testing Measurement Invariance.' Structural Equation Modeling 9 (2): 233-255.

DeBardeleben, Joan. 1991. To Breathe Free: Eastern Europe's Environmental Crisis. Washington, DC: The Johns Hopkins University Press.

DeBardeleben, Joan. 1997. 'Environmental Consciousness and Economic Development.' Pp. 147-168 in Shades of Green: Environmental Attitudes in Canada and around the World, edited by A. Frizzell and J. Pammett. Ottawa: Carleton University Press.

Diekmann, Andreas and Axel Franzen. 1999. 'The Wealth of Nations and Environmental Concern.' Environment and Behavior 31 (4): 540-549.

Dietz, Thomas, Linda Kalof and Paul C. Stern. 2002. 'Gender, Values and Environmentalism.' Social Science Quarterly 83 (1): 353-364.

Dietz, Thomas, Paul Stern and Gregory Guagnano. 1998. 'Social Structural and Social Psychological Bases of Environmental Concern.' Environment and Behavior 30: 450-471.

Dunlap, Riley, George Gallup and Alec Gallup. 1993. 'Of Global Concern: Results of the Health of the Planet Survey.' Environment 35 (9): 7-40.

Dunlap, Riley and Robert Jones. 2002. 'Environmental Concern: Conceptual and Measurement Issues.' Pp. 482-524 in Handbook of Environmental Sociology, edited by R. Dunlap and W. Michelson. Westport, CT: Greenwood Press.

Dunlap, Riley and Angela Mertig. 1995. 'Global Concern for the Environment: Is Affluence a Prerequisite?' Journal of Social Issues 51: 121-137.

Dunlap, Riley and Angela Mertig. 1997. 'Global Environmental Concern: An Anomaly for Postmaterialism.' Social Science Quarterly 78 (1): 24-29. 
Dunlap, Riley, Kent D. Van Liere, Angela Mergit and Roberta Jones. 2000. 'Measuring Endorsement of the New Ecological Paradigm: A Revived NEP Scale.' Journal of Social Issues 56 (3): 425-442.

Dunlap, Riley, Chenyang Xiao and Aaron McCright. 2002. 'Politics and Environment in America: Partisan and Ideological Cleavages in Public Support for Environmentalism.' Environmental Politics 10: 23-48.

Dunlap, Riley and Richard York. 2008. 'The Globalization of Environmental Concern and the Limits of the Postmaterialist Values Explanation: Evidence from Four Multinational Surveys.' The Sociological Quarterly 49 (3): 529-563.

Franzen, Axel. 2003. 'Environmental Attitudes in International Comparison: An Analysis of the ISSP Surveys 1993 and 2000.' Social Science Quarterly 83: 297-308.

Franzen, Axel and Reto Meyer. 2010. 'Environmental Attitudes in Cross-National Perspective: A Multilevel Analysis of the ISSP 1993 and 2000.' European Sociological Review 26 (2): 219-234.

Gelissen, John. 2007. 'Explaining Popular Support for Environmental Protection: A Multilevel Analysis of 50 Nations.' Environment and Behavior 39 (3): 392-415.

Givens, Jennifer and Andrew Jorgenson. 2011. 'The Effects of Affluence, Economic Development, and Environmental Degradation on Environmental Concern: A Multilevel Analysis.' Organization and Environment 24 (1): 74-91.

Haller, Max and Markus Hadler. 2008. 'Dispositions to Act in Favor of the Environment: Fatalism and Readiness to Make Sacrifices in Cross-National Perspective.' Sociological Forum 23 (2): 281-311.

Hayes, Bernadette. 2001. 'Gender, Scientific Knowledge and Attitudes Toward the Environment: A Cross-National Analysis.' Political Research Quarterly 54: 657-671.

Heyns, Barbara. 2005. 'Emerging Inequalities in Central and Eastern Europe.' Annual Review of Sociology 31: 163-197.

$\mathrm{Hu}, \mathrm{Li}-\mathrm{Tze}$ and Peter Bentler. 1999. 'Cutoff Criteria for Fit Indexes in Covariance Structure Analysis: Conventional Criteria versus New Alternatives.' Structural Equation Modeling 6 (1): 1-55.

Inglehart, Ronald. 1995. 'Public Support for Environmental Protection: The Impact of Objective Problems and Subjective Values in 43 Societies.' PS: Political Science and Politics (March): 57-71.

International Social Survey Programme. 2003. International Social Survey Programme (ISSP), 1985-2000. (CD-ROM) Cologne: Zentralarchiv für Empirische Sozialforschung an der Universität zu Köln.

Jancar-Webster, Barbara. 1995. 'The Environmental Legacies of Communism.' Pp. 84-100 in The Legacies of Communism in Eastern Europe, edited by Z. Barany and I. Volgyes. Baltimore, MD: The Johns Hopkins University Press.

Jones, Robert and Riley Dunlap. 1992. 'The Social Bases of Environmental Concern: Have They Changed Over Time?' Rural Sociology 57: 28-47.

Jorgenson, Andrew. 2011. 'Carbon Dioxide Emissions in Central and Eastern European Nations, 1992-2005: A Test of Ecologically Unequal Exchange Theory.' Human Ecology Review 18: 105-114.

Kemmelmeier, Markus, Grzegorz Krol and Young Hun Kim. 2002. 'Values, Economics, and Pro-Environmental Attitudes in 22 Societies.' Cross-Cultural Research 36 (3): 256-285.

Kidd, Quentin and Aie-Rie Lee. 1997. 'Post-materialist Values and the Environment: A Critique and Reappraisal.' Social Science Quarterly 78 (1): 1-15.

Kline, Rex. 2010. Principles and Practice of Structural Equation Modeling. New York: The Guilford Press. 
Klineberg, Stephen, Matthew McKeever and Bert Rothenbach. 1998. 'Demographic Predictors of Environmental Concern: It Does Make a Difference How It's Measured.' Social Science Quarterly 79 (4): 734-753.

Mahutga, Matthew and Nina Bandelj. 2008. 'Foreign Investment and Income Inequality: The Natural Experiment of Central and Eastern Europe.' International Journal of Comparative Sociology 49 (6): 429-454.

Marquart-Pyatt, Sandra T. 2007. 'Concern for the Environment Among General Publics: A Cross-National Study.' Society and Natural Resources 20 (10): 883-898.

Marquart-Pyatt, Sandra T. 2008. 'Are There Similar Influences on Environmental Concern?: Comparing Industrialized Countries.' Social Science Quarterly 89 (5): 1-24.

Milanović, Branko. 1996. 'Income, Inequality and Poverty During the Transition: A Survey of the Evidence.' MOCT-MOST 6: 131-147.

Pavlinek, Petr and John Pickles. 2000. Environmental Transitions: Transformation and Ecological Defence in Central and Eastern Europe. New York: Routledge.

Steenbergen, Marco and Bradford Jones. 2002. 'Modeling Multilevel Data Structures.' American Journal of Political Science 46: 218-237.

United Nations Development Programme (UNDP). 2010. Human Development Report 2010: The Real Wealth of Nations: Pathways to Human Development. New York: Palgrave Macmillan and UNDP.

World Bank. 2010. World Development Report 2010: Development and Climate Change. Washington, DC: World Bank Publishers.

Xiao, Chenyang and Riley Dunlap. 2007. 'Validating a Comprehensive Model of Environmental Concern Cross-Nationally: A US-Canadian Comparison.' Social Science Quarterly 88: 471-493.

York, Richard. 2009. 'De-carbonization in Former Soviet Republics, 1992-2000:

The Ecological Consequences of De-modernization.' Social Problems 55 (3): 370-390. 